\title{
Endoscopy of the vertically stapled stomach
}

\author{
STEPHEN N SUlLIVAN, MD, FRCPC, FRCP(LONDON), RONALD HOLLIDAY, MD, FRCSC
}

\begin{abstract}
S Sullivan, R HollidaY. Endocopy of the vertically stapled stomach. Can J Gastroenterol 1993;7(7):568-570. Over a five-year period, 145 morbidly obese patients were treated by vertical banded gastroplasty. In a follow-up ranging from six months to five and one-half years, 29 developed upper gastrointestinal symptoms severe enough to require consultation and endoscopy. Vomiting of solid food was the most common symptom. Eight patients had stomal stenosis (which was treated by endoscopic and bougie dilation in five, while three required gastrogastrostomy to relieve obstruction). In four patients the only endoscopic abnormality was marked laxity of the lower esophageal sphincter which was confirmed manometrically. Only one patient had Marlex mesh erosion.
\end{abstract}

Key Words: Complications, Endoscopy, Gastroplasty, Obesity

\section{Endoscopie d'un estomac agrafé à la verticale}

RÉSUMÉ: Sur une période de 5 ans, 145 patients gravement obèses ont été traités par gastroplastie pratiquée à la verticale. Lors de périodes de suivi variant de six mois à cinq ans et demi, 29 patients ont présenté des symptômes digestifs hauts suffisamment graves pour nécessiter une consultation et une endoscopie. Les vomissements d'aliments solides étaient le symptôme le plus fréquent. Huit patients présentaient une sténose stomacale qui a été dilatée par endoscopie et bougie chez cinq d'entre eux, alors que trois autres ont nécessité une gastrogastrostomie pour dégager l'obstruction. Chez quatre patients seulement, l'anomalie endoscopique était une laxité marquée du sphincter œesophagien inférieur, confirmée par manométrie. Un seul patient a présenté une érosion due à la mèche de Marlex.

$S$ JRGERY HAS BECOME A POPULAR approach to the management of morbid obesity. Vertical banded gastroplasty (VBG) is currently the technique in favour (1). It involves creating a small pouch along the lesser curvature of the stomach in continuity with the esophagus. The emptying of the pouch is limited by wrapping the outlet with Marlex mesh (CR Bard Inc, Massachu-

Departments of Medicine and Surgery, Victoria Hospital, London, Ontario

Correspondence: Dr Stephen N Sullivan, King Fahad National Guard Hospital, PO Box 22490, Riyadh 11426, Saudi Arabia

Received for publication May 27, 1992. Accepted November 30, 1992

setts) or a similar material. Compared with other surgical techniques, it is safe and relatively easy to perform (2).

In 1985, after the authors became disillusioned with the complications of horizontal banded gastroplasty (HBG) and noted an unacceptably high rate of erosion of the Marlex mesh into the pouch stoma, they switched to performing VBG and report their findings in those patients who subsequently developed upper gastrointestinal symptoms troublesome enough to require endoscopy.

\section{PATIENTS AND METHODS}

Between January 1985 and December 1989,145 morbidly obese patients (20 males, 125 females) underwent VBG at the authors' institution. All operations were performed by one surgeon using the method described by Mason (1). A 50 to $60 \mathrm{~mL}$ vertical pouch was created using stapling instruments. The first 80 patients had Marlex mesh placed about the lesser curve gastric stoma, which was calibrated with a 32 French Maloney bougie. The last 65 patients had the stoma reinforced with Gortex (WL Gore and Associates Ltd, United Kingdom). The Gortex and Marlex mesh were premeasured $(7.5 \mathrm{~cm}$ by $1.5 \mathrm{~cm}$ ) and secured with an overlap of approximately $1 \mathrm{~cm}$ to give a circumference of $5.5 \mathrm{~cm}$. The rest of the technique was done in routine fashion. The patients were reviewed regularly and 
those who developed troublesome upper gastrointestinal symptoms were referred for endoscopy.

\section{RESULTS}

Until June 1990, 29 patients developed gastrointestinal symptoms severe enough to require endoscopy. Twentyone $(72 \%)$ presented with postprandial nausea and vomiting of solids. Other symptoms included abdominal pain (six, 20\%), dysphagia (four, 14\%), heartburn (four, $14 \%$ ) and regurgitation without heartburn (five, $17 \%$ ). These patients underwent 46 endoscopic procedures. The endoscopic findings are listed in Table 1. The most common significant finding was that of stomal stenosis (found in eight). These patients underwent 19 dilations with an olympus GIF type Q 20 endoscope $(11 \mathrm{~mm})$ or semirigid Savary-Gilliard bougies over a guidewire; the maximum diameter bougie used was $17 \mathrm{~mm}$, with most patients managed with dilation up to $14 \mathrm{~mm}$. The symptoms of three patients with stomal stenosis could not be managed by repeated dilation, and they were treated with gastrogastrostomy.

Only one patient had erosion of the Marlex mesh into the stoma. This patient had been taking ibuprofen. The ulceration healed after stopping ibuprofen and use of cimetidine, but patency of the stoma could not be maintained and she required gastrogastrostomy.

Six patients with postprandial vomiting had complete incompetence of the lower esophageal sphincter at endoscopy. Inflation of the esophagus with air $5 \mathrm{~cm}$ above the sphincter allowed one to look down to the stoma directly; there was no evidence of a functional sphincter. Four of these patients who had otherwise normal endoscopies without stomal stenosis underwent esophageal manometry with a pneumohydraulically perfused catheter system. All had weak lower esophageal sphincters with pressures of 5, 5, 8 and $10 \mathrm{mmHg}$. One patient with dysphagia had a tightly closed sphincter at endoscopy. She had esophageal manometry and radionuclide esophageal transit studies, highly suggestive of early achalasia.

\section{DISCUSSION}

In 1988 Fardy and colleagues (3) published endoscopic experience of morbidly obese patients who had been treated by HBG. Fifty of the $138 \mathrm{pa}$ tients developed upper gastrointestinal symptoms requiring gastrointestinal consultation and endoscopy.

Sixty-eight per cent ( 34 of 50) had stomal stenosis and $24 \%$ (12 of 50 ) had developed Marlex erosion into the stoma. Many of these patients had to be managed by gastrogastrostomy or conversion to a VBG. This unacceptably high rate of complications in HBG has been recognized by others (4).

Accordingly, in 1985 the current authors changed their method of surgical management of morbid obesity to VBG. Compared with HBG, we are very pleased with the weight loss and the low rate of complications with VBG (as are others [2,5-12]). In the presented patient population, only one patient developed Marlex mesh erosion, but this patient was also taking ibuprofen, a medication with known ulcerogenic potential. This low rate of mesh or ring erosion in VBG is wellrecognized, (5,7-9,13,14). However, during the current study one patient who had been operated on at another institution and developed stomal ulceration and mesh erosion while being treated with $40 \mathrm{mg}$ omeprazole daily for esophagitis was seen. This dose of omeprazole virtually abolishes gastric acid secretion and had healed his esophagitis. He was treated by gastrogastrostomy but others have described the endoscopic removal of eroded mesh (15). Clearly, acid is not needed for mesh erosion.

Stenosis of the stoma occurs infrequently - only $5.5 \%$ in this study. Stenosis can usually be managed by endoscopic, balloon or bougie dilation $(12-14,16)$.

\section{CONCLUSIONS}

The symptoms and endoscopic findings of the current patients are very similar to those recently reported by Wayman (17). However, an unexpected endoscopic finding which has not been mentioned by others was marked incompetence of the lower

\section{TABLE 1}

Endoscopic findings*

\begin{tabular}{lc}
\hline Finding & Number (\%) \\
\hline Normal & $11(24 \%)$ \\
Stomal stenosis & $8(17 \%)$ \\
Esophagitis & $7(15 \%)$ \\
Lax lower esophageal & $6(13 \%)$ \\
$\quad$ sphincter & \\
Stomal ulcer & $3(6 \%)$ \\
Staple line dehiscence & $2(4 \%)$ \\
Eroded staple/suture & $2(4 \%)$ \\
Marlex erosion & $1(2 \%)$ \\
\hline
\end{tabular}

46 procedures in 29 patients

esophageal sphincter in four patients with vomiting and regurgitation who had otherwise normal endoscopies. Weakness of the lower esophageal sphincter was confirmed manometrically. In spite of their massive obesity none of these patients had troublesome symptoms of gastroesophageal reflux prior to $\mathrm{VBG}$, raising the possibility that overeating and distension of the pouch and distal esophagus by food and fluid might lead to incompetence of the lower esophageal sphincter. This possibility would be worth investigating prospectively by a preoperative esophageal manometry and follow-up manometry in patients who developed symptoms of regurgitation postoperatively.

\section{REFERENCES}

1. Mason EE. Vertical banded gastroplasty for obesity. Arch Surg 1982;117:701-5.

2. Yale CE. Gastric surgery for morbid obesity. Arch Surg 1989;124:941-6.

3. Fardy J, Holliday R, Sullivan S. Marlex mesh erosion: A complication of horizontal banded gastroplasty. Gastrointest Endoscopy 1988;34:461-2.

4. Grace DM. Recognition and management of Marlex erosion after transverse gastroplasty for morbid obesity. Can J Surg 1987;30: 282-5.

5. Bogokowski H, Slutzki S, Waron M, et al. Vertical banded gastroplasty for the treatment of morbid obesity. J Clin Gastroenterol 1988;10:655-8.

6. MacLean LD, Rhode BM, Forse RA. Late results of vertical banded gastroplasty for morbid and superobesity. Surgery 1990;107:20-7.

7. Deitel M, Jones DA, Petrov I, Wlodarczyk SR, Basi S. Vertical banded gastroplasty: Results in 233 patients. Can J Surg 1986;29:322-4. 
8. Eckhout GV, Willbanks OL, Moore JT. Vertical ring gastroplasty for morbid obesity: Five year experience with 1,463 patients. Am J Surg 1986;152:713-6.

9. Owen ERTC, Abraham R, Kark AE. Gastroplasty for morbid obesity: Technique, complications and results in 60 cases. Br J Surg 1989;76:131-5.

10. Andersen T, Pedersen BH, Dissing I, Astrup A, Henriksen JH. A randomized comparison of horizontal and vertical banded gastroplasty: What determines weight loss? Scand J Gastroenterol 1989;24:186-92.
11. Carr ND, Harrison RA, Tomkins A, et al. Vertical banded gastroplasty in the treatment of morbid obesity: Results of three-year follow-up. Gut 1989;30:1048-53.

12. Hocking MP, Kelly KA, Callaway $\mathrm{CW}$. Vertical gastroplasty for morbid obesity: Clinical experience. Mayo Clin Proc 1986;61:287-91.

13. Scapa E, Negri M, Halpern Z, Bogokowsky H, Eshchar J. Endoscopic diagnosis and management and complications of vertical banded gastroplasty. Endoscopy 1988;20:11-2.

14. Deitel M, Bendago M. Endoscopy of vertical banded gastroplasty. Am Surg 1989;55:287-90.

15. Subramanyam K, Robbins HT. Erosion of Marlex band and silastic ring into the stomach after gastroplasty: Endoscopic recognition and management. Am J Gastroenterol 1989;84:1319-21.

16. Sataloff DM, Lieber CP, Seinige UL. Strictures following gastric stapling for morbid obesity: Results of endoscopic dilatation. Am Surg 1990;56:167-74.

17. Wayman CS, Nord HJ, Combs WM, Rosemurgy AS. The role of endoscopy after vertical banded gastroplasty. Gastrointest Endosc 1992;38:44-6. 


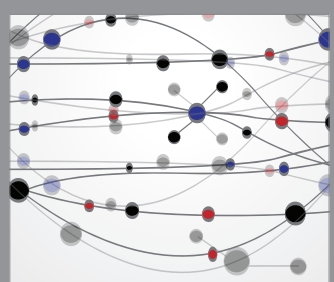

The Scientific World Journal
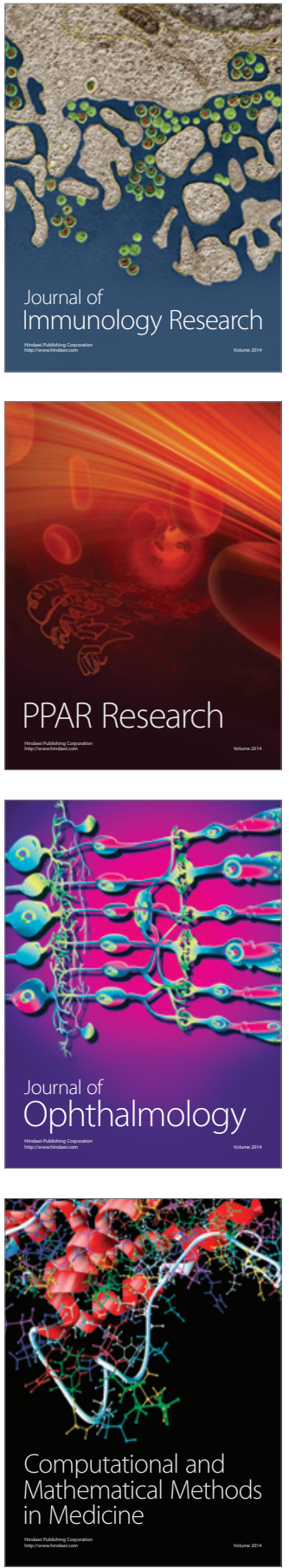

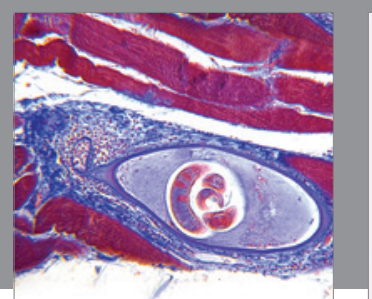

Gastroenterology Research and Practice

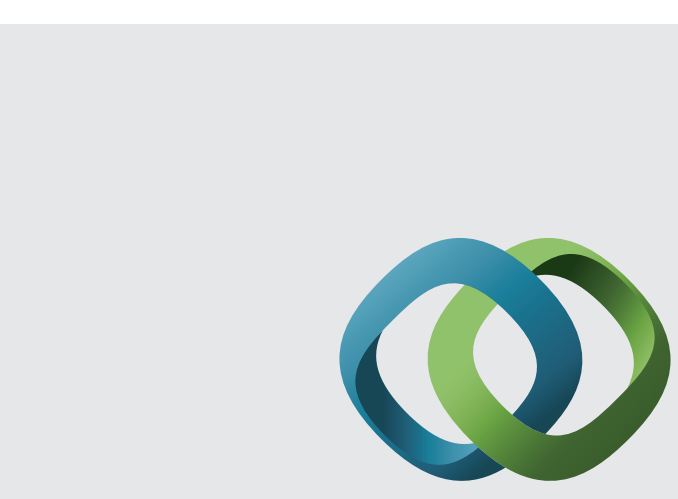

\section{Hindawi}

Submit your manuscripts at

http://www.hindawi.com
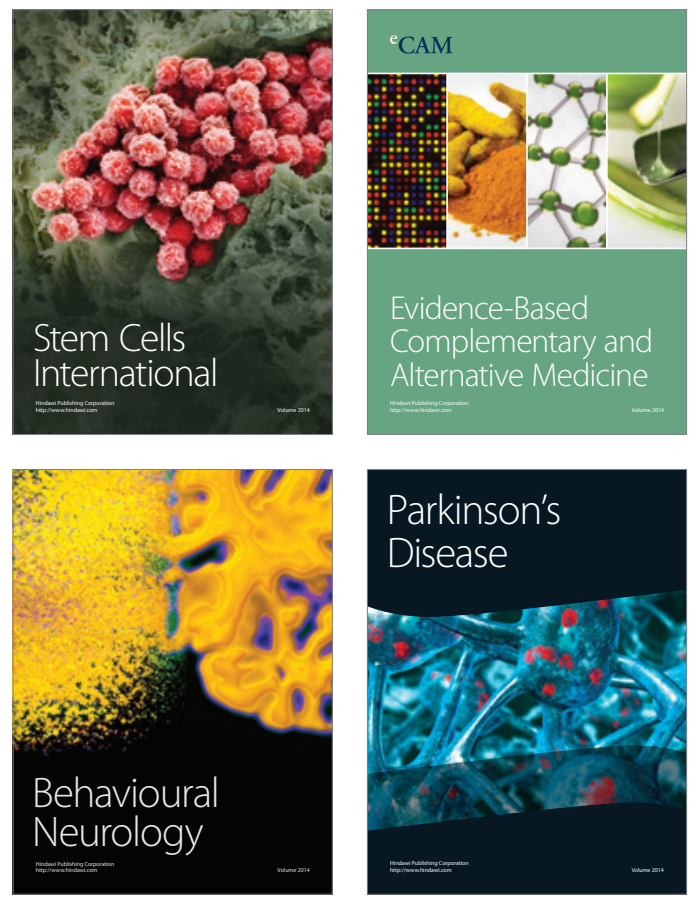
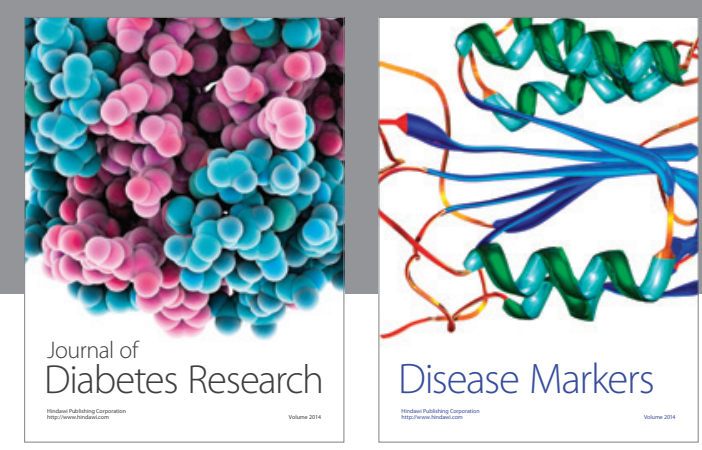

Disease Markers
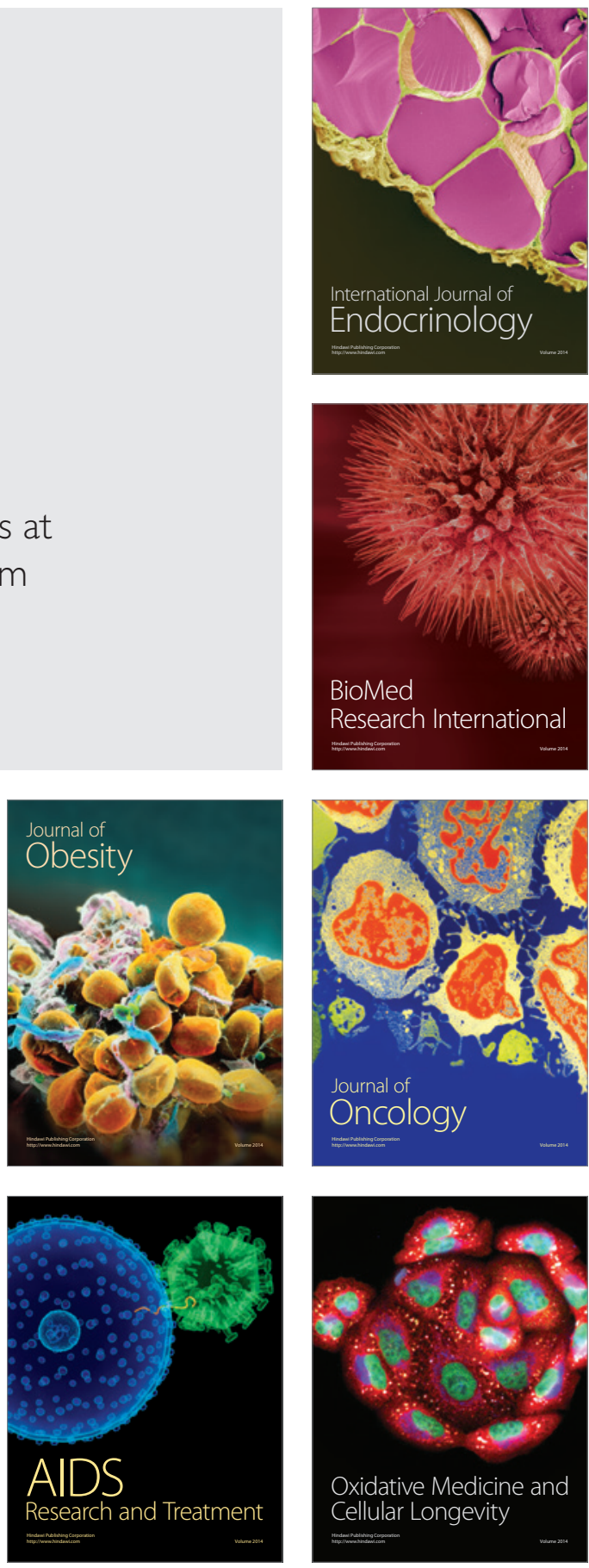